\title{
Ibrutinib inhibits SDF1/CXCR4 mediated migration in AML
}

\author{
Lyubov Zaitseva ${ }^{1}$, Megan Y. Murray ${ }^{1}$, Manar S. Shafat ${ }^{1}$, Matthew J. Lawes ${ }^{3}$, David \\ J. MacEwan ${ }^{2}$, Kristian M. Bowles ${ }^{1,3}$ and Stuart A. Rushworth ${ }^{1}$ \\ ${ }^{1}$ Department of Molecular Haematology, Norwich Medical School, University of East Anglia, Norwich Research Park, Norwich, \\ United Kingdom \\ 2 Department of Molecular and Clinical Pharmacology, Institute of Translational Medicine, University of Liverpool, Liverpool, \\ United Kingdom \\ ${ }^{3}$ Department of Haematology, Norfolk and Norwich University Hospitals NHS Trust, Colney Lane, Norwich United Kingdom \\ Correspondence to: Stuart Rushworth, email: s.rushworth@uea.ac.uk
}

Keywords: AML, BTK, Ibrutinib, CXCR4, SDF1

Received: July 04, $2014 \quad$ Accepted: September 15, $2014 \quad$ Published: September 16, 2014

This is an open-access article distributed under the terms of the Creative Commons Attribution License, which permits unrestricted use, distribution, and reproduction in any medium, provided the original author and source are credited.

\section{ABSTRACT}

Pharmacological targeting of BTK using ibrutinib has recently shown encouraging clinical activity in a range of Iymphoid malignancies. Recently we reported that ibrutinib inhibits human acute myeloid leukemia (AML) blast proliferation and leukemic cell adhesion to the surrounding bone marrow stroma cells. Here we report that in human AML ibrutinib, in addition, functions to inhibit SDF1/CXCR4-mediated AML migration at concentrations achievable in vivo. It has previously been shown that SDF1/CXCR4-induced migration is dependent on activation of downstream BTK in chronic lymphocytic leukaemia (CLL) and multiple myeloma. Here we show that SDF-1 induces BTK phosphorylation and downstream MAPK signalling in primary AML blast. Furthermore, we show that ibrutinib can inhibit SDF1-induced AKT and MAPK activation. These results reported here provide a molecular mechanistic rationale for clinically evaluating BTK inhibition in AML patients and suggests that in some AML patients the blasts count may initially rise in response to ibrutinib therapy, analgous to similar clinical observations in CLL.

\section{INTRODUCTION}

Despite recent significant progress in the understanding of the biology of AML the clinical outcomes for the majority of patients diagnosed with AML presently remain poor. AML is primarily a disease of the elderly[1], and for most of the $75 \%$ of patients aged over 60 at diagnosis long term survival has barely improved in the last 40 years [2], largely because the intensity and side effects of existing curative therapeutic strategies (which are commonly used to treat the younger fitter patients) coupled to patient co-morbidities, frequently limit their use in this older less fit population. Consequently, there is an urgent need to identify pharmacological strategies in AML, which are not only effective but can be tolerated by the older, less well patient. It is envisaged that treatments which target tumor-specific biology will help realise this goal.

Bruton's Tyrosine Kinase (BTK) is a non- receptor tyrosine kinase that belongs to the Tec family and clearly has an important function in a number of benign and malignant cells of the haematopoietic system [3-7]. Moreover, recent phase 1, 2 and 3 studies of the irreversible oral BTK inhibitor, ibrutinib have demonstrated excellent clinical activity and tolerability against a variety of B-cell malignancies including, chronic lymphocytic leukemia (CLL), mantle cell lymphoma, hairy cell leukaemia and diffuse large B-cell lymphoma in younger and older patients alike [8-16]. Furthermore, it is now clear that the mechanism of action [MOA] of ibrutinib is multifactorial in nature with a significant component of its function in lymphoid malignancy involving disruption of the interaction between the tumor cell and the microenvironment that protects it. Recently our group and others have shown that there is high BTK phosphorylation and RNA expression in AML [17-19]. Moreover, our recent study described for the first time that ibrutinib and BTK-targeted RNA interference reduced 
factor-induced proliferation of both AML cell lines and primary AML blasts, as well as reducing AML blast adhesion to BMSC [19].

Inhibition of BTK has been shown to regulate CLL, MCL and MM cell migration by inhibiting SDF1 (stromal derived factor 1) induced CXCR4 regulated cell trafficking [20-22]. SDF1 is an extracellular chemokine which is abundantly produced by the bone marrow microenvironment binds to and activates its receptor CXCR4 which is highly expressed on many non-malignant and malignant cells including breast cancer cell, normal haematopoietic CD34+ cells as well as AML blasts [23, 24]. In this study we investigate the role of BTK inhibition on the function of SDF-1/CXCR4 in AML. Furthermore, we examine the intracellular signalling cascade down stream of SDF1/CXCR4 activation, specifically the effects on AKT and MAPK. Finally, we examine the role of BTK RNAi on SDF-1/CXCR4-mediated AML migration.

\section{RESULTS}

\section{Ibrutinib inhibits AML cell migration in response to SDF-1}

Previously we have shown that ibrutinib inhibits AML proliferation and adhesion to BMSC. In myeloma and CLL ibrutinib inhibits CXCR4/SDF1-mediated migration [11, 25]. Moreover, inhibition of CXCR4/SDF1 axis using AMD3100 (Plerixafor), an agonist for CXCR4, has been shown to decrease AML tumor burden in AML leukaemic mice in combination with conventional AML chemotherapy [26]. Therefore we initially examined the expression of CXCR4 in human AML cell lines and found that $4 / 4$ cell lines were positive for CXCR4 expression (Figure 1A). Next we examined the effects of ibrutinib on the migration of the AML cell lines U937, MV4-11, HL60 and THP-1 in response to SDF1. Figure 1B shows that ibrutinib can inhibit the migration of all AML cell lines tested. Finally, we tested the in-vitro activity of ibrutinib on SDF-1 induced migration in a spectrum of primary AML blasts from a wide age spectrum of adult patients and across a range of WHO AML subclasses (Table 1). Figure 1C shows that ibrutinib significantly inhibits primary AML blast migration $(n=12)$. Taken together these data show that ibrutinib inhibits SDF1/CXCR4 driven migration in human AML.

\section{BTK is activated in response to SDF-1 in human AML}

Since SDF1 has been shown to mediate migration of AML in a CXCR4 dependent mechanism and that SDF1/CXCR4-induced migration is dependent on activation of downstream BTK in CLL, myeloma and normal B cells $[21,27]$, we examined the activity of BTK phosphorylation and downstream AKT and MAPK in response to SDF1 and found that SDF1 increases levels of pBTK and downstream MAPK in primary AML blasts (Figure 2A). Since CXCR4 activation has been shown to mediate downstream MAPK and AKT activity [28, 29], we examined if ibrutinib could inhibit SDF1 induced MAPK and AKT signalling in primary AML blast. Figure 2B shows that ibrutinib inhibits SDF1 induced BTK, MAPK and AKT phosphorylation in AML at concentrations equivalent to those that can be achieved in vivo (based on ibrutinib $420 \mathrm{mg}$ orally once a day) $[10,16]$. These results demonstrate that ibrutinib inhibits CXCR4 mediated signalling in primary human AML cells.

\section{Pharmacological inhibition of $G$ proteins inhibits SDF1 induced BTK activation}

Since CXCR4 is a Gi-coupled receptor and pertussis toxin inhibits Gi-coupled receptor activation [30], we used pertussis toxin to determine if SDF1 induces phosphorylation of BTK through CXCR4. To do this we treated AML cell line MV4-11 with pertussis toxin for 15 mins before the addition of SDF1 for $10 \mathrm{mins}$. Figure $3 \mathrm{~A}$ shows that pertussis toxin can inhibit SDF1 mediated phospoBTK activation in AML blasts. Next we wanted to determine if inhibition of CXCR4 activation by pertussis toxin as well as inhibition of downstream AKT and MAPK , could also block SDF1 induced migration of AML cell line MV4-11. Figure 3B shows that pertussis toxin, PD98059 and AKT inhibitor VIII could all inhibit SDF1 induced migration in MV4-11 cells.

\section{Knockdown of BTK inhibits SDF1 induced migration in AML}

It has been shown that ibrutinib has multiple kinase targets including interleukin-2-inducible kinase [31], as well as other members of the TEC kinase family. Therefore to eliminate the problems associated with off target inhibitor activity we evaluated migration of AML cells lines using genetic inhibition of BTK. To do this we generated lentivirus-mediated long-term BTK knockdown using targeted artificial microRNA (BTKtargeted miRNA) and visualisation of infected cells by a concurrently expressed GFP signal tag as previously described [19]. The introduction of BTK-specific miRNA dramatically inhibited the expression of BTK in THP-1 and HL60 (Figure 4A). Next we examined the role of mRNA targeted BTK knockdown on THP-1 and HL60 migration. Figure 4B shows that AML cells with BTK$\mathrm{KD}$ had reduced SDF1 mediated migration confirming that BTK is involved in regulating AML migration in response to SDF1. Figure 4C shows a schematic of how BTK targets SDF1/CXCR4 signalling in AML. 


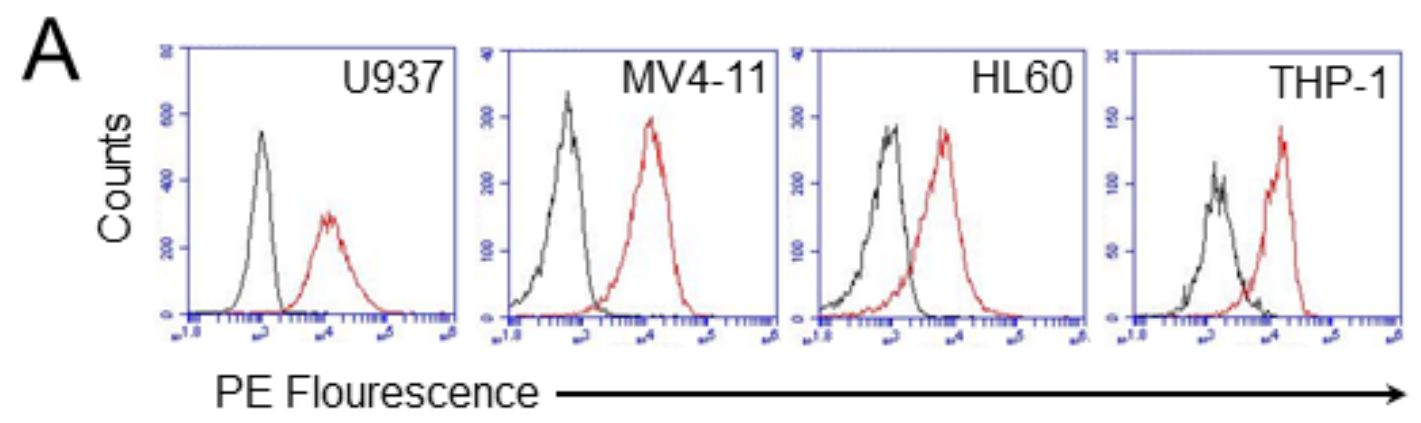

B

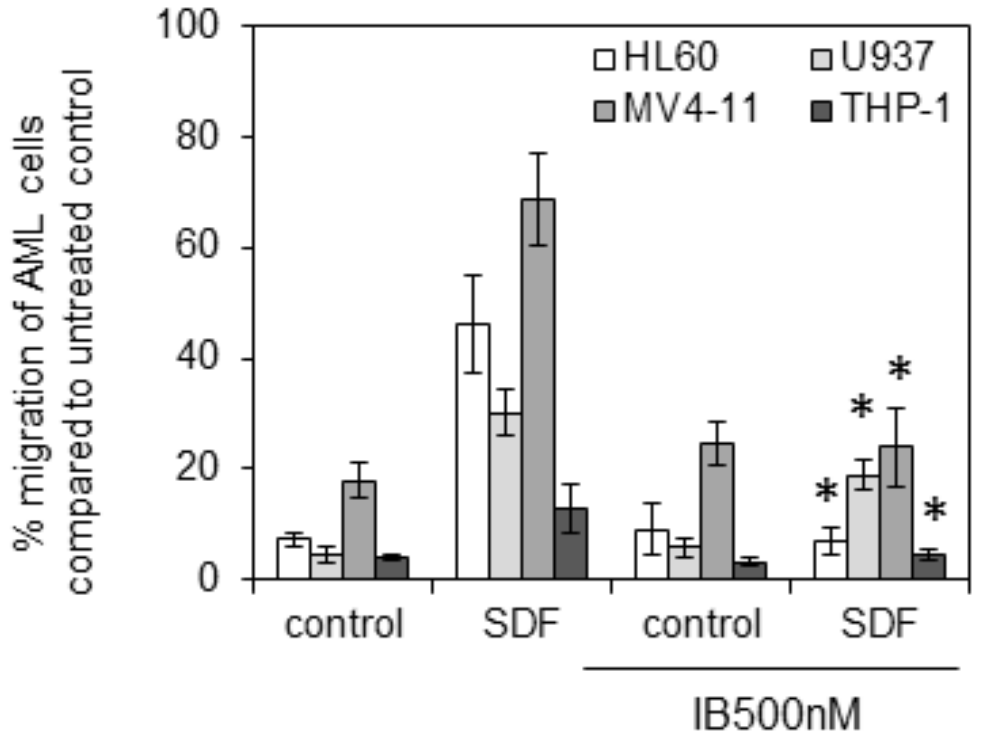

C
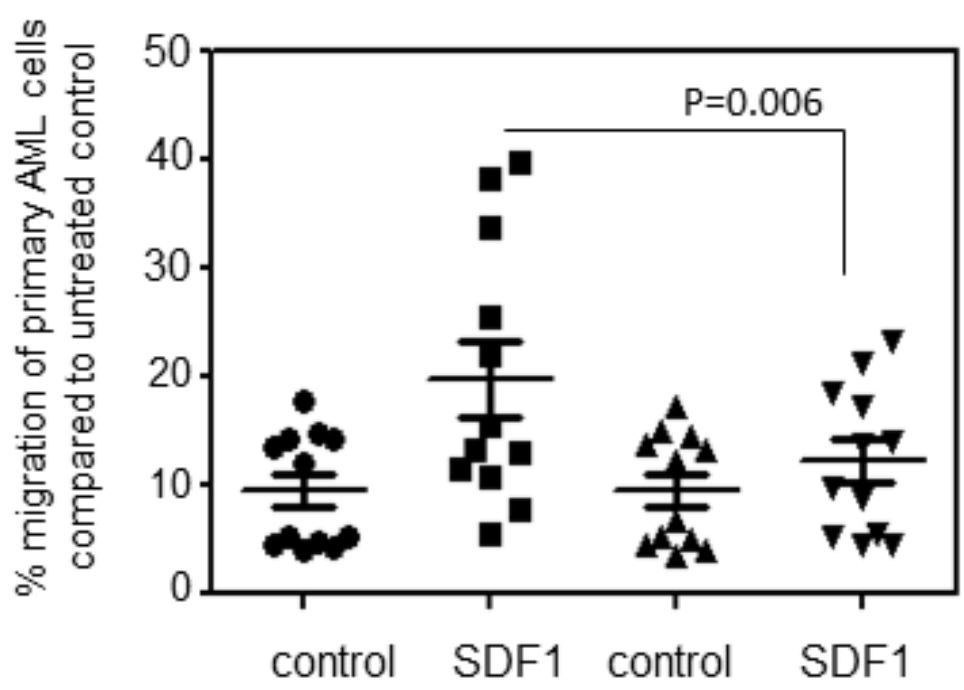

IB500nM

Figure 1: Ibrutinib inhibits AML cell migration in response to SDF-1 (A). AML cell lines were examined for CXCR4 expression ( $\mathrm{n}=4$ ) using flow cytometry (B) AML cell lines were pretreated with 500nM of ibrutinib for $1 \mathrm{~h}$ before wash off and then placed in the upper well of a $8.0 \mu \mathrm{M}$ transwell plate. The lower chamber contained 500ul of serum free media supplemented with SDF1 (100 ng/ml) for 3 hours and then assessed for cell number using a flow cytometer. Data were normalised to DMSO treated cells. *statistical significance. (C) Primary AML blasts $(\mathrm{n}=12)$ were pretreated with ibrutinib $(500 \mathrm{nM})$ for $1 \mathrm{~h}$ before wash off and then placed in the upper well of a $8.0 \mu \mathrm{M}$ transwell plate. The lower chamber contained 500ul of serum free media supplemented with SDF1 (100 ng/ml) for $3 \mathrm{hours}$ and then assessed for cell number using a flow cytometer. Data were normalised to DMSO treated cells. 
Table 1: AML patient sample information. This table defines the nature of the AML disease including WHO diagnosis and cytogenetics.

\begin{tabular}{|c|c|c|c|c|c|}
\hline Number & Age & Gender & \multicolumn{2}{|c|}{ WHO diagnosis } & \multicolumn{2}{|c|}{ Cytogenetics $\%$ Blasts } \\
\hline AML\#1 & 82 & $\mathrm{M}$ & AML NOS & not available & $65 \%$ \\
\hline AML\#2 & 47 & $\mathrm{M}$ & AML without maturation & not available & $90 \%$ \\
\hline AML\#3 & 55 & $\mathrm{~F}$ & Acute monoblastic and monocytic leukaemia & normal & $80 \%$ \\
\hline AML\#4 & 41 & $\mathrm{~F}$ & AML with t(6;9)(p23;q34);DEK-NUP214 & t(6;9) & $>95 \%$ \\
\hline AML\#5 & 77 & $\mathrm{~F}$ & AML with maturation & normal & $65 \%$ \\
\hline AML\#6 & 70 & $\mathrm{M}$ & AML with minimal differentiation & normal & $>95 \%$ \\
\hline AML\#7 & 40 & $\mathrm{M}$ & AML with minimal differentiation & normal & $90 \%$ \\
\hline AML\#8 & 70 & $\mathrm{M}$ & AML without maturation & complex & $95 \%$ \\
\hline AML\#9 & 91 & $\mathrm{~F}$ & AML NOS & not available & $60 \%$ \\
\hline AML\#10 & 55 & $\mathrm{~F}$ & AML relapsed & not available & $70 \%$ \\
\hline AML\#11 & 59 & $\mathrm{~F}$ & AML with t(8;21)(q22;q22); RUNX1- & t(8;21) & $80 \%$ \\
\hline AML\#12 & 51 & M & AML with monocytic differentiation & normal & $95 \%$ \\
\hline
\end{tabular}
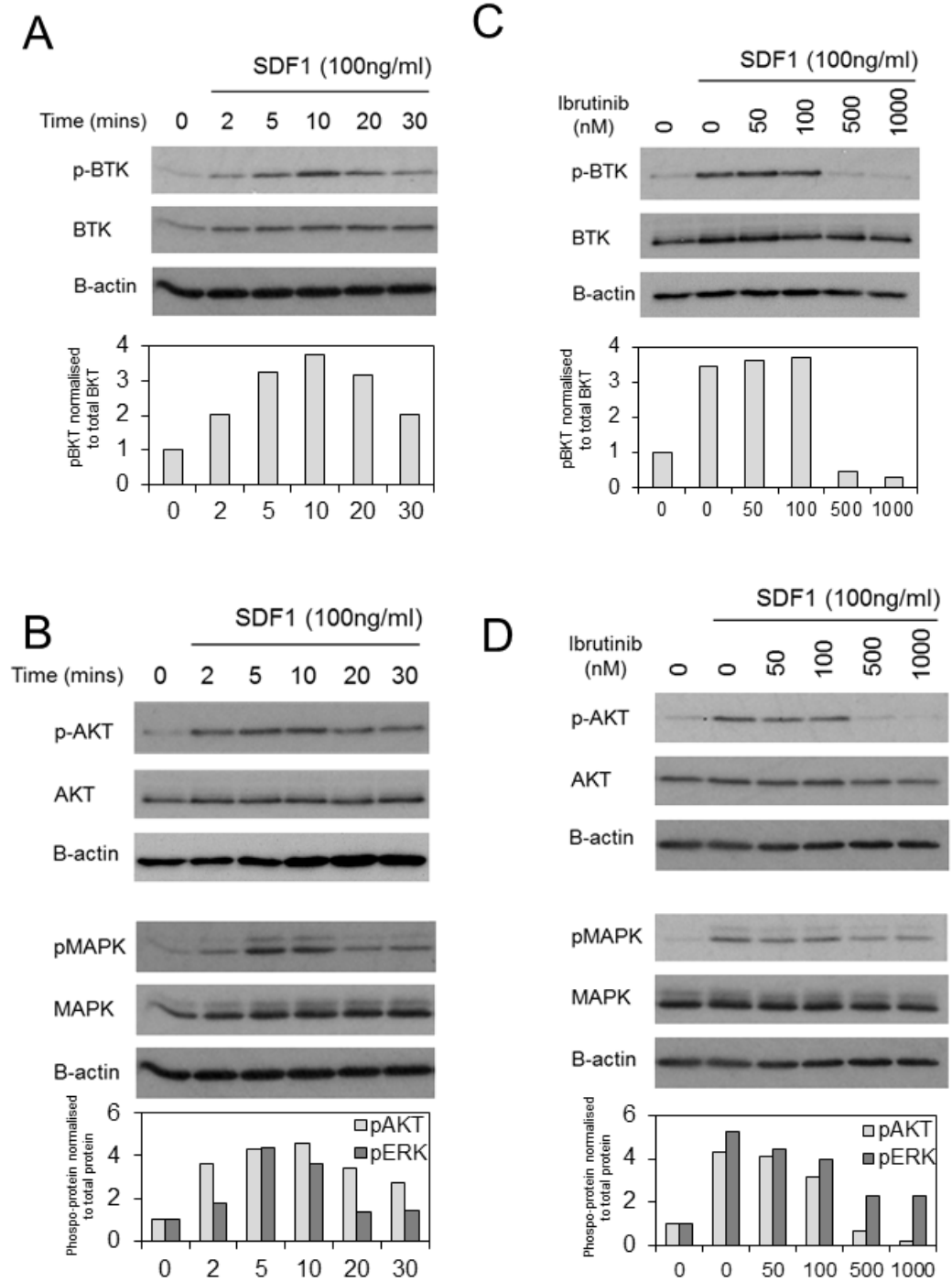

Figure 2: BTK is activated in response to SDF-1 in human AML. (A) AML blasts were treated with SDF1 (100 ng/ml) for indicated times. Protein extracts were obtained and Western blot analysis was conducted for pBTK, BTK, pMAPK, MAPK and $\beta$-actin protein levels. (B) AML blasts were pretreated with increasing concentrations of ibrutinib for $1 \mathrm{~h}$ and then treated with SDF1 (100 ng/ml) for 10 mins. Protein extracts were obtained and Western blot analysis was conducted for pATK, ATK, pMAPK, MAPK and $\beta$-actin protein levels. These results are representative of experiments which were repeated three times with the bar graphs showing mean expression (as measured by densitometry) compared to control from all 3 experiments. 
A

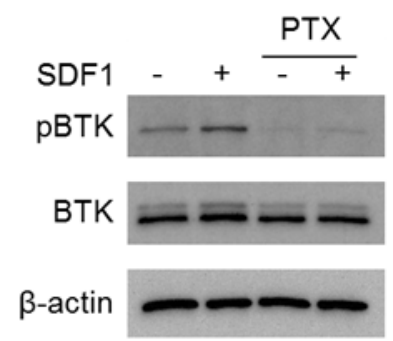

$\mathrm{B}$

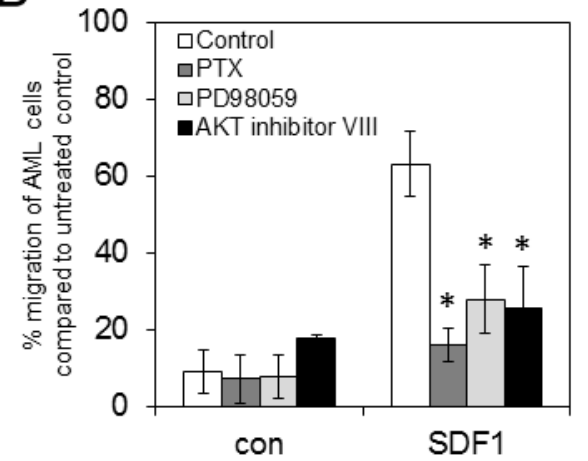

Figure 3: Pharmacological inhibition of G-proteins, AKT and ERK block SDF1 induced migration in AML. (A) MV4-11 cells were pretreated with pertussis toxin $(100 \mathrm{ng} / \mathrm{ml})$ for 30 mins and then stimulated with SDF1 for 10mins. Protein extracts were obtained and Western blot analysis was conducted for pBTK, BTK and $\beta$-actin protein levels. These results are representative of experiments which were repeated three times. (B) MV4-11 cells were pretreated with pertussis toxin $(100 \mathrm{ng} / \mathrm{ml})$, PD98059 $(20 \mu \mathrm{M})$ and AKT inhibitor VIII $(2 \mu \mathrm{M})$ for $30 \mathrm{mins}$ and then placed in the upper well of a $8.0 \mu \mathrm{M}$ transwell plate. The lower chamber contained 500ul of serum free media supplemented with SDF1 $(100 \mathrm{ng} / \mathrm{ml})$ for 3 hours and then assessed for cell number using a flow cytometer. Data were normalised to DMSO treated cells. *statistical significance compared to SDF1 MV4-11 cells.
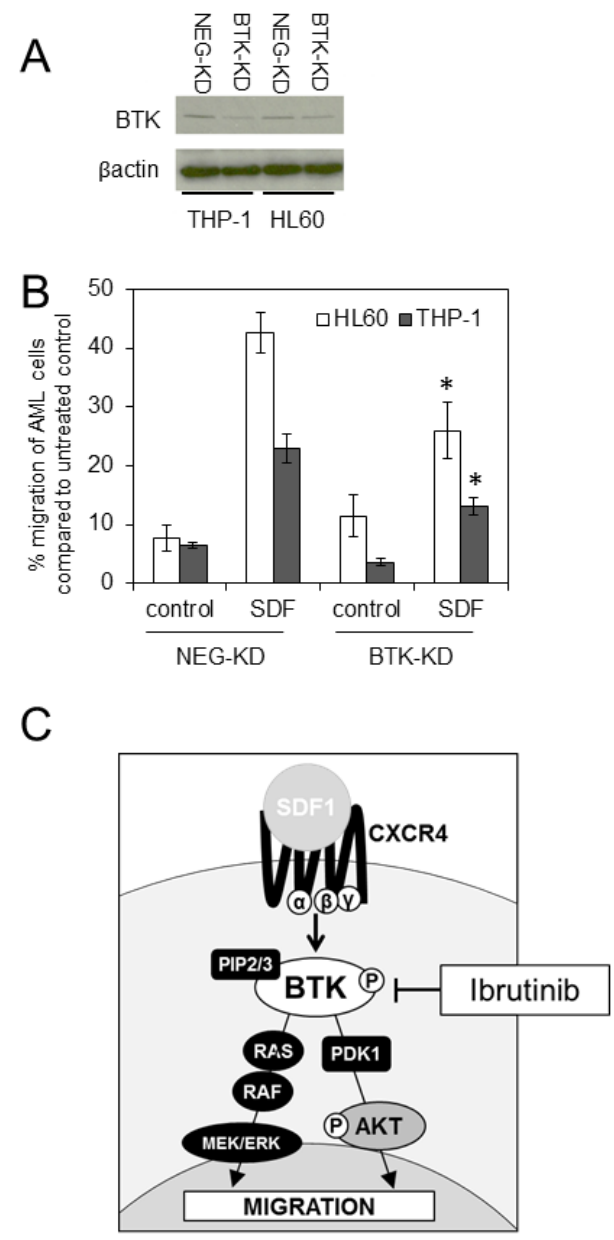

Figure 4: Knockdown of BTK inhibits SDF1 induced migration in AML. (A) AML cell lines (HL60 and THP-1) were transduced with BTK-targeted miRNA (BTK-KD) or a negative-targeted miRNA (NEG-KD) GFP-tagged lentiviral constructs for $72 \mathrm{~h}$. Protein extracts were obtained and Western blot analysis was conducted for BTK and $\beta$-actin protein levels. These results are representative of experiments which were repeated three times (B) HL60 and THP-1 were transduced with BTK-KD and NEG-KD lentivirus for $72 \mathrm{~h}$ and then placed in the upper well of a $8.0 \mu \mathrm{M}$ transwell plate. The lower chamber contained 500ul of serum free media supplemented with SDF1 $(100 \mathrm{ng} / \mathrm{ml})$ for 3 hours and then assessed for cell number using a flow cytometer. Data were normalised to NEG-KD cells. *statistical significance. (C) Schematic to show the role of BTK inhibition by ibrutinib in preventing AML migration. 


\section{DISCUSSION}

BTK is a cytoplasmic tyrosine kinase widely expressed in hematopoietic cells and long known to be critical in B cell differentiation and survival pathways. BTK is a member of the BTK/Tec family of tyrosine kinases [32]. BTK activation has been implicated in a variety of hematopoietic cellular responses and there is a growing literature supporting the role of BTK in HSC and cells of the myeloid compartment [33-35]. Previously we have shown that ibrutinib inhibits AML adhesion to BMSC. In the present study we develop on these findings to investigate the effect of BTK inhibition using ibrutinib on AML blast migration.

In CLL and other B cell malignancies ibrutinib inhibits SDF1/CXCR4-induced tumor cell migration $[20,25]$. We hypothesised that SDF1/CXCR4 signalling was also regulated by BTK in AML. Inhibition of CXCR4 signalling using the CXCR4 inhibitor AMD3100 (Plerixafor) can mobilise non-malignant hematopoietic stem cells from the bone marrow in to the peripheral blood for harvesting[36]. Moreover, in AML AMD3100 has been shown to increase the level of AML cells in the peripheral blood and therefore increase their sensitivity to chemotherapy in murine models [26]. Our data confirm that ibrutinib targets SDF1/CXCR4 signalling.

Ibrutinib has been shown to be well tolerated with limited grade 3 and 4 toxicity across a broad age range of patients with CLL and MCL $[5,15,16]$. Since AMD3100 inhibits SDF1-mediated non-malignant CD34+ cell migration we also expect ibrutinib to do the same, however, as we have observed previously we expect ibrutinib to inhibit pro-survival signals including SCF mediated and to a lesser extent IL-3 and GM-CSF in AML [19]. The clinical significance of the ibrutinib effect on non-malignant HSC in patients with AML can only be defined in the context of clinical trials.

In patients with CLL treated with ibrutinib an initial and sometimes persistent rise in the circulating lymphocyte count may be seen, even in the context of clinically responding disease [8]. This is believed to occur in part because of an egress of malignant cells from nodal compartments[37]. In AML blocking of SDF/CXCR4 by AMD3100 is associated with a rise in circulating tumour cells[26]. In light of these reports and our own findings that Ibrutinib inhibits CXCR4/SDF1 mediated migration in AML we hypothesise that in some AML patients the blast count may initially rise in response to ibrutinib therapy. However while the rising lymphocyte count in CLL causes no known harm to the patient, an uncontrolled rise in the blast count in AML may put patients at risk of leucostasis. Accordingly we suggest future clinical trial protocols of BTK inhibition in human AML should include strategies to manage a rising blast count (such as addition of cytoreductive chemotherapy) should it occur.

Here we show for the first time that in human AML ibrutinib inhibits SDF1/CXCR4 pathway and functions to disrupt migration signals from the microenvironment This study further validates an emerging focus of targeting kinases critical for the survival of malignant cells and gives us a clearer understanding of how inhibition of BTK may optimally be harnessed therapeutically in AML. In summary, we provide additional scientific support for clinical trials of ibrutinib in patients with AML.

\section{METHODS}

\section{Materials}

Anti-phosphorylated and pan AKT, BTK and MAPK antibodies were purchased from Cell Signaling Technology (Cambridge, MA). Anti-CD34-PE and antiCXCR4-FITC antibodies were purchased from Miltenyi Biotec (Auburn, CA). Ibrutinib was obtained from Selleck Chemicals. SDF1 was purchased from Miltenyi Biotec. Pertusis toxin was purchased from R\&D systems (Abingdon, UK). LY294002 and U0126 were purchased from Cell Signalling Technology. All other reagents were obtained from Sigma-Aldrich (St Louis, MO), unless indicated.

\section{Cell culture}

AML cells were obtained from patients' bone marrow or blood following informed consent and under approval from the UK National Research Ethics Service (LRECref07/H0310/146). For primary cell isolation, heparinized blood was collected from volunteers and human peripheral blood mononuclear cells (PBMCs) isolated by Histopaque (Sigma-Aldrich, UK) density gradient centrifugation. AML samples that were less than $80 \%$ blasts were purified using the CD34 positive selection kit (denoted by * in Table 1). Cell type was confirmed by microscopy and flow cytometry as previously described [38].

The AML-derived cell lines were obtained from the DMSZ (German Collection of Microorganisms and Cell Cultures) and European Collection of Cell Cultures where they are authenticated by DNA-fingerprinting. In the laboratory they are used at low passage number for a maximum of 6 months post-resuscitation, testing regularly for Mycoplasma infection

\section{Virus construction and infection}

$$
\text { MicroRNA sequence miRNA-BTK }
$$

(5'-TTCACTGGACTCTTCACCTCT-3') targeting human BTK was selected with Invitrogen Block-iT RNAi Designer software (www.invitrogen.com/rnai) and plasmid 
pcDNATM6.2-GW/EmGFP-miR-neg (Invitrogen) was used as source for negative control as previously described [19] [38].

\section{Western immunoblotting}

Sodium dodecyl sulfate-polyacrylamide gel electrophoresis and Western blot analyses were performed as described previously. Briefly, whole cell lysates as well as nuclear and cytosolic were extracted and sodium dodecyl sulfate-polyacrylamide gel electrophoresis separation performed $[39,40]$. Protein was transferred on nitrocellulose membrane and Western blot analysis performed with the indicated antisera according to their manufacturer's guidelines

\section{Migration Assays}

Migration assays were performed in triplicate in Transwell permeable plates with $8.0 \mu \mathrm{M}$ pores (Costar). The lower compartment contained $500 \mu \mathrm{L}$ of serum free media supplemented with $100 \mathrm{ng} / \mathrm{ml} \mathrm{SDF} 1$ and the cells were applied to the upper compartment and allowed to migrate for $3 \mathrm{~h}$. The amount of viable migrated cells was determined by counting using trypan blue exclusion and expressed as a percentage of the input. The bars represent the means $\pm \mathrm{SD}$ of at least three independent experiments, each assayed in triplicate.

\section{Statistical analyses}

Student's T test was performed to assess statistical significance from controls. Results with $\mathrm{P}<0.05$ were considered statistically significant $(*)$. Results represent the mean \pm SD of 3 independent experiments. For Western blotting, data are representative images of 3 independent experiments.

\section{ACKNOWLEDGEMENTS}

The authors wish to thank the Worldwide Cancer Research, National Institutes for Health Research (Flexibility and Sustainability Funding) and The Big C.

\section{Authorship Contributions}

SAR, KMB and LZ designed the research. SAR, LZ, MSS and MYM performed the research. MJL provided essential reagents. SAR, KMB and DJM wrote the paper.

\section{Disclosure of Conflicts of Interest}

The authors declare no conflicts of interest.

\section{REFERENCES}

1. Juliusson G, Antunovic P, Derolf A, Lehmann S, Mollgard L, Stockelberg D, Tidefelt U, Wahlin A, Hoglund M. Age and acute myeloid leukemia: real world data on decision to treat and outcomes from the Swedish Acute Leukemia Registry. Blood. 2009, 113:4179-4187.

2. Burnett A: Ham-Wasserman Lecture. In; https://ash.confex. com/ash/2012/webprogram/Session3976.html. 2012.

3. Ezell SA, Mayo M, Bihani T, Tepsuporn S, Wang S, Passino M, Grosskurth SE, Collins M, Parmentier J, Reimer C, Byth KF. Synergistic induction of apoptosis by combination of BTK and dual mTORC1/2 inhibitors in diffuse large B cell lymphoma. Oncotarget. 2014, 5:49905001.

4. Tai YT, Anderson KC. Bruton's tyrosine kinase: oncotarget in myeloma. Oncotarget. 2012, 3:913-914.

5. Rushworth SA, Macewan DJ, Bowles KM. Ibrutinib in Relapsed Chronic Lymphocytic Leukemia. New England Journal of Medicine. 2013, 369:1278-1279.

6. Honda F, Kano H, Kanegane H, Nonoyama S, Kim E-S, Lee S-K, Takagi M, Mizutani S, Morio T. The kinase Btk negatively regulates the production of reactive oxygen species and stimulation-induced apoptosis in human neutrophils. Nat Immunol. 2012, 13:369-378.

7. Horwood NJ, Page TH, McDaid JP, Palmer CD, Campbell J, Mahon T, Brennan FM, Webster D, Foxwell BMJ. Bruton's Tyrosine Kinase Is Required for TLR2 and TLR4Induced TNF, but Not IL-6, Production. The Journal of Immunology. 2006, 176:3635-3641.

8. Byrd JC, Brown JR, O'Brien S, Barrientos JC, Kay NE, Reddy NM, Coutre S, Tam CS, Mulligan SP, Jaeger U, Devereux S, Barr PM, Furman RR et al. Ibrutinib versus Ofatumumab in Previously Treated Chronic Lymphoid Leukemia. N Engl J Med. 2014.

9. Burger JA, Buggy JJ. Emerging drug profiles: Bruton tyrosine kinase (BTK) inhibitor ibrutinib (PCI-32765). Leuk Lymphoma. 2013.

10. Advani RH, Buggy JJ, Sharman JP, Smith SM, Boyd TE, Grant B, Kolibaba KS, Furman RR, Rodriguez S, Chang BY, Sukbuntherng J, Izumi R, Hamdy A et al. Bruton tyrosine kinase inhibitor ibrutinib (PCI-32765) has significant activity in patients with relapsed/refractory B-cell malignancies. Journal of clinical oncology : official journal of the American Society of Clinical Oncology. 2013, 31:88-94.

11. Tai Y-T, Chang BY, Kong S-Y, Fulciniti M, Yang G, Calle Y, Hu Y, Lin J, Zhao J-J, Cagnetta A, Cea M, Sellitto MA, Zhong MY et al. Bruton's tyrosine kinase inhibition is a novel therapeutic strategy targeting tumor in the bone marrow microenvironment in multiple myeloma. Blood. 2012.

12. Kim E, Koehrer S, Rosin NY, Thomas DA, Ravandi F, Kornblau SM, Kantarjian HM, O'Brien S, Estrov Z, 
Buggy JJ, Burger JA. Activity of Bruton's Tyrosine Kinase (BTK) Inhibitor Ibrutinib (PCI-32765) in B-Cell Acute Lymphoblastic Leukemia (B-ALL). ASH Annual Meeting Abstracts. 2012, 120:2569.

13. Sivina M, Kreitman RJ, Arons E, Buggy JJ, Ravandi F, Burger JA. Bruton's Tyrosine Kinase (BTK) Inhibitor Ibrutinib (PCI-32765) Blocks Hairy Cell Leukemia (HCL) Survival, Proliferation, and BCR Signaling: A New Therapeutic Approach for HCL. ASH Annual Meeting Abstracts. 2012, 120:1802.

14. Dasmahapatra G, Patel H, Dent P, Fisher RI, Friedberg J, Grant S. The Bruton tyrosine kinase (BTK) inhibitor PCI-32765 synergistically increases proteasome inhibitor activity in diffuse large-B cell lymphoma (DLBCL) and mantle cell lymphoma (MCL) cells sensitive or resistant to bortezomib. British Journal of Haematology. 2013, 161:4356.

15. Wang ML, Rule S, Martin P, Goy A, Auer R, Kahl BS, Jurczak W, Advani RH, Romaguera JE, Williams ME, Barrientos JC, Chmielowska E, Radford J et al. Targeting BTK with Ibrutinib in Relapsed or Refractory Mantle-Cell Lymphoma. New England Journal of Medicine. 2013, 0:null.

16. Byrd JC, Furman RR, Coutre SE, Flinn IW, Burger JA, Blum KA, Grant B, Sharman JP, Coleman M, Wierda WG, Jones JA, Zhao W, Heerema NA et al. Targeting BTK with Ibrutinib in Relapsed Chronic Lymphocytic Leukemia. New England Journal of Medicine. 2013, 369:32-42.

17. Tomasson MH, Xiang Z, Walgren R, Zhao Y, Kasai Y, Miner T, Ries RE, Lubman O, Fremont DH, McLellan MD, Payton JE, Westervelt P, DiPersio JF et al. Somatic mutations and germline sequence variants in the expressed tyrosine kinase genes of patients with de novo acute myeloid leukemia. Blood. 2008, 111:4797-4808.

18. Gu T-1, Nardone J, Wang Y, Loriaux M, Villén J, Beausoleil S, Tucker M, Kornhauser J, Ren J, MacNeill J, Gygi SP, Druker BJ, Heinrich MC et al. Survey of Activated FLT3 Signaling in Leukemia. PLoS ONE. 2011, 6:e19169.

19. Rushworth SA, Murray MY, Zaitseva L, Bowles KM, MacEwan DJ. Identification of Bruton's tyrosine kinase as a therapeutic target in acute myeloid leukemia. Blood. 2014, 123:1229-1238.

20. Chang BY, Francesco M, De Rooij MF, Magadala P, Steggerda SM, Huang MM, Kuil A, Herman SE, Chang S, Pals ST, Wilson W, Wiestner A, Spaargaren M et al. Egress of CD19+CD5+ cells into peripheral blood following treatment with the Bruton tyrosine kinase inhibitor ibrutinib in mantle cell lymphoma patients. Blood. 2013, 122:24122424.

21. Bam R, Ling W, Khan S, Pennisi A, Venkateshaiah SU, Li X, van Rhee F, Usmani S, Barlogie B, Shaughnessy J, Epstein J, Yaccoby S. Role of Bruton's tyrosine kinase in myeloma cell migration and induction of bone disease. Am J Hematol. 2013, 88:463-471.

22. Burger JA. Nurture versus Nature: The Microenvironment in Chronic Lymphocytic Leukemia. ASH Education Program Book. 2011, 2011:96-103.

23. Ablett MP, O'Brien CS, Sims AH, Farnie G, Clarke RB. A differential role for CXCR4 in the regulation of normal versus malignant breast stem cell activity. Oncotarget. 2014, 5:599-612.

24. Mohle R, Bautz F, Rafii S, Moore MA, Brugger W, Kanz L. The chemokine receptor CXCR-4 is expressed on CD34+ hematopoietic progenitors and leukemic cells and mediates transendothelial migration induced by stromal cell-derived factor-1. Blood. 1998, 91:4523-4530.

25. de Rooij MFM, Kuil A, Geest CR, Eldering E, Chang BY, Buggy JJ, Pals ST, Spaargaren M. The clinically active BTK inhibitor PCI-32765 targets B-cell receptor- and chemokine-controlled adhesion and migration in chronic lymphocytic leukemia. Blood. 2012, 119:2590-2594.

26. Nervi B, Ramirez P, Rettig MP, Uy GL, Holt MS, Ritchey JK, Prior JL, Piwnica-Worms D, Bridger G, Ley TJ, DiPersio JF. Chemosensitization of acute myeloid leukemia (AML) following mobilization by the CXCR4 antagonist AMD3100. Blood. 2009, 113:6206-6214.

27. de Gorter DJ, Beuling EA, Kersseboom R, Middendorp S, van Gils JM, Hendriks RW, Pals ST, Spaargaren M. Bruton's tyrosine kinase and phospholipase Cgamma2 mediate chemokine-controlled B cell migration and homing. Immunity. 2007, 26:93-104.

28. Azab AK, Runnels JM, Pitsillides C, Moreau A-S, Azab F, Leleu X, Jia X, Wright R, Ospina B, Carlson AL, Alt C, Burwick N, Roccaro AM et al. CXCR4 inhibitor AMD3100 disrupts the interaction of multiple myeloma cells with the bone marrow microenvironment and enhances their sensitivity to therapy. Blood. 2009, 113:4341-4351.

29. Alsayed Y, Ngo H, Runnels J, Leleu X, Singha UK, Pitsillides CM, Spencer JA, Kimlinger T, Ghobrial JM, Jia X, Lu G, Timm M, Kumar A et al. Mechanisms of regulation of CXCR4/SDF-1 (CXCL12)-dependent migration and homing in multiple myeloma. Blood. 2007, 109:2708-2717.

30. Kaslow HR, Burns DL. Pertussis toxin and target eukaryotic cells: binding, entry, and activation. Faseb j. 1992, 6:26842690.

31. Dubovsky JA, Beckwith KA, Natarajan G, Woyach JA, Jaglowski S, Zhong Y, Hessler JD, Liu TM, Chang BY, Larkin KM, Stefanovski MR, Chappell DL, Frissora FW et al. Ibrutinib is an irreversible molecular inhibitor of ITK driving a Th1-selective pressure in T lymphocytes. Blood. 2013, 122:2539-2549.

32. de Weers M, Verschuren MCM, Kraakman MEM, Mensink RGJ, Schuurman RKB, van Dongen JJM, Hendriks RW. The Bruton's tyrosine kinase gene is expressed throughout B cell differentiation, from early precursor B cell stages preceding immunoglobulin gene rearrangement up to mature B cell stages. European Journal of Immunology. 1993, 23:3109-3114. 
33. Schmidt U, van den Akker E, Parren-van Amelsvoort M, Litos G, de Bruijn M, Gutiérrez L, Hendriks RW, Ellmeier W, Löwenberg B, Beug H, von Lindern M. Btk Is Required for an Efficient Response to Erythropoietin and for SCF-controlled Protection against TRAIL in Erythroid Progenitors. The Journal of Experimental Medicine. 2004, 199:785-795.

34. Fiedler K, Sindrilaru A, Terszowski G, Kokai E, Feyerabend TB, Bullinger L, Rodewald H-R, Brunner C. Neutrophil development and function critically depend on Bruton tyrosine kinase in a mouse model of X-linked agammaglobulinemia. Blood. 2011, 117:1329-1339.

35. Fiedler K, Kokai E, Bresch S, Brunner C. MyD88 is involved in myeloid as well as lymphoid hematopoiesis independent of the presence of a pathogen. Am J Blood Res. 2013, 3:124-140.

36. Larochelle A, Krouse A, Metzger M, Orlic D, Donahue RE, Fricker S, Bridger G, Dunbar CE, Hematti P. AMD3100 mobilizes hematopoietic stem cells with long-term repopulating capacity in nonhuman primates. Blood. 2006, 107:3772-3778.

37. Woyach JA, Bojnik E, Ruppert AS, Stefanovski MR, Goettl VM, Smucker KA, Smith LL, Dubovsky JA, Towns WH, MacMurray J, Harrington BK, Davis ME, Gobessi S et al. Bruton's tyrosine kinase (BTK) function is important to the development and expansion of chronic lymphocytic leukemia (CLL). Blood. 2014, 123:1207-1213.

38. Rushworth SA, Zaitseva L, Langa S, Bowles KM, MacEwan DJ. FLIP regulation of HO-1 and TNF signalling in human acute myeloid leukemia provides a unique secondary antiapoptotic mechanism. Oncotarget. 2011, 1:359-366.

39. Heasman SA, Zaitseva L, Bowles KM, Rushworth SA, MacEwan DJ. Protection of acute myeloid leukaemia cells from apoptosis induced by front-line chemotherapeutics is mediated by haem oxygenase-1. Oncotarget. 2011, 2:658668.

40. Rushworth SA, MacEwan DJ. HO-1 underlies resistance of AML cells to TNF-induced apoptosis. Blood. 2008, 111:3793-3801. 